\title{
MIGRACIÓN INTERNACIONAL Y CAMBIO SOCIOCULTURAL EN LA COMUNidAd INDígena de COYUTLA, VeraCRUZ
}

\author{
International Migration and Sociocultural Change \\ IN THE INDigenOUS COMMUNiTy OF COYUTLA, VeraCRUZ
}

\author{
Mario Pérez Monterosas* \\ doi: https://doi.org/10.31644/ED.V9.N1.2022.A07
}

\begin{abstract}
Resumen: Las movilidades regionales de carácter laboral y las migraciones a los Estados Unidos que tienen lugar en el totonacapan veracruzano han dinamizado la circulación no solo de personas, sino también de bienes, información, dinero, objetos, narrativas y expectativas, dejando su impronta en el territorio, en las formas del trabajo agrícola y de relacionarse con la tierra. Consideramos que han traído la aceleración de procesos de cambio y resignificación de los procesos socioculturales locales y los valores materiales y simbólicos de los campesinos. En este trabajo realizado en la cabecera municipal de Coyutla, Veracruz, nos acercamos a las dinámicas migratorias, las transformaciones de los contextos rurales y la vida cotidiana, tanto de las personas que se van y regresan como de quienes se quedan. Esta investigación se fundamenta en la información obtenida en trabajo de campo, recorridos in situ, entrevistas y pláticas informales con migrantes de retorno y sus familiares en Coyutla en el año de 2012.
\end{abstract}

Palabras clave: migración internacional, migración de indígenas, proceso sociocultural, Coyutla, Veracruz.

Abstract: Regional labor mobility and migrations to the United States have boosted the circulation
not only of people, but also of goods, information, money, objects, narratives and expectations,
leaving their mark on the territory, in agricultural work and in the kind of relationship with the land
in the region of Totonacapan, Veracruz. We consider that it has accelerated change and redefinition
of local socio-cultural processes, as well as material and symbolic values of peasants. In this work,
carried out in the municipal capital of Coyutla, Veracruz, we approach the migratory dynamics,
the transformations of rural contexts and the daily life of people who leave and return, just as

* Dr. en Historia y Estudios Regionales, profesor investigador Departamento de Sociología Universidad Autónoma Metropolitana Azcapotzalco, México. ORCiD: https://orcid.org/0000-0003-1648-1294. Correo-e: marpezrosa@gmail.com.

Fecha de recepción: 13/11/2020. Fecha de aceptación: 08/07/2021. Fecha de publicación: 31/01/2022.

\section{(cc) BY-NC-ND}

EntreDiversidades. Revista de Ciencias Sociales y Humanidades, Vol. 9, Núm. 1 (18), enero-junio 2022. Páginas: 176-199 ISSN-e: 2007-7610. https://doi.org/10.31644/ED.V9.N1.2022.A07 
of those who stay. This research is based on information obtained in field work, on-site trecks, interviews, and informal talks with returning migrants and their families, in Coyutla in 2012.

Keywords: international migration, indigenous migration, sociocultural process, Coyutla, Veracruz.

\section{Introducción}

En este artículo analizamos las dinámicas de movilidad regional laboral, la migración a los Estados Unidos, las interacciones sociales y los cambios que se han acelerado en la sierra Papanteca, que comprende los municipios de Filomeno Mata, Mecatlán, Espinal y Coyutla. En concreto, en este último es en el que centramos nuestra investigación para dar cuenta sobre cómo estas dinámicas han impactado en la vida cotidiana, así como en la redefinición de los procesos socioculturales y las relaciones con la tierra. Las movilidades de los indígenas de Coyutla, Veracruz, más allá del Estado-nación y su participación en el mantenimiento de la agricultura local a través de las remesas económicas y de la reproducción de patrones culturales relacionados con la tierra, nos permiten reflexionar a partir de aquello que Bourdieu y Sayad (2017) denominan "espíritu campesino", que comprende valores y sistemas de pensamiento que circulan en diversas direcciones por el mundo rural expandido.

Consideramos hipotéticamente que las migraciones influyen de manera importante en la idea y percepción de lo que debería ser el trabajo, la tierra o la búsqueda de ingresos económicos fuera de la comunidad de origen, y que las interacciones sociales permean de elementos tangibles e intangibles el contexto rural e indígena complejizando gradualmente las dinámicas de reproducción social y económica. El municipio de Coyutla vive en los comienzos del siglo XXI momentos cruciales, donde a la agricultura se le asigna una importancia diferente: la relación con la tierra se ha desvalorizado y el trabajo en el campo tiene otro significado para los jóvenes, y los sistemas de organización se vinculan más allá de lo regional e incluso de lo nacional a través de la tecnología o las migraciones, haciendo circular ideas, dinero, personas, objetos, prácticas, expectativas y sueños que dan otra dimensión a la reproducción social.

El presente estudio se basa en el análisis y reflexión de la información obtenida en trabajo de campo etnográfico. Realizado en la cabecera municipal de Coyutla, durante tres estancias de una semana cada una en el año 2012, consistió en recorridos de campo, observación participante, entrevistas abiertas y cerradas, uso de fotografía, cartografía y conversaciones informales con autoridades locales e integrantes de organizaciones de la sociedad civil como la Asociacion Rural de Interés Colectivo-Coyutla y Movimiento Agrario Indígena Zapatista, A.C. ${ }^{1}$ Las personas

\footnotetext{
${ }^{1}$ La investigación en el totonacapan veracruzano se ha venido realizando en diferentes temporadas entre 2011, 2012, 2013 y 2015, durante las cuales se hizo trabajo de campo etnográfico en algunas comunidades de los municipios de Espinal, Mecatlán, Filomeno Mata y Coyutla (Pérez, 2018b). Al respecto, se han publicado hallazgos y avances que abordan los temas de las redes sociales y rutas migratorias que los totonacos de la sierra de Papantla han conformado en las últimas tres décadas (Pérez, 2018a), así como sobre la migración de retorno y los efectos en los factores socioemocionales tanto de los que retornan de Estados Unidos como de las y los que se quedan, un estudio de caso que tiene lugar en el municipio de Coyutla (Pérez, 2016).
}

EntreDiversidades. Revista de Ciencias Sociales y Humanidades, Vol. 9, Núm. 1 (18), enero-junio 2022. Páginas: 176-199 ISSN-e: 2007-7610. https://doi.org/10.31644/ED.V9.N1.2022.A07 
de quienes se obtuvo información empírica de la experiencia migratoria internacional fueron habitantes indígenas y mestizos del pueblo de Coyutla, migrantes de retorno, mujeres que se quedaban a cargo del hogar durante la ausencia del esposo o de los hijos, jóvenes estudiantes de la Universidad Veracruzana Intercultural y aquellos que se identificaron a través de la técnica bola de nieve y que conocían las dinámicas de los mercados de trabajo regional, la migración y el cambio sociocultural.

El presente documento se compone de tres apartados. En el primero de ellos se plantea el escenario local multicultural y social complejo de lo rural en contexto de movilidades y participación del trabajo agrícola remunerado, y su influencia en el desdibujamiento del ser campesino e indígena. En el segundo apartado se presentan las dinámicas de movilidad regional e internacional relacionadas con el mundo del trabajo que influyen en las formas de concebir la tierra y las expectativas de futuro en la región de la Sierra de Papantla. El tercero aborda las transformaciones socioculturales que han traído consigo de manera acelerada la participación en el fenómeno migratorio hacia los Estados Unidos en las décadas recientes. Finalmente, se exponen algunas conclusiones.

\section{Escenario local multicultural y social complejo}

Considerar el fenómeno de la migración como lo hace la información oficial, es decir, como "el cambio de residencia de una o varias personas de manera temporal o definitiva, generalmente con la intención de mejorar su situación económica, así como su desarrollo personal y familiar" (INEGI, 2021), nos parece insuficiente para contextualizarlo en la realidad actual. Por ello, coincidimos con Rivera en definir "la migración no como proceso dicotómico y unidireccional o bidireccional entre lugar de origen y lugar de destino, sino como un proceso que involucra múltiples destinos y movilidades diversas" (2012: 31) en un contexto social. Por tanto, nos referimos a la movilidad, circulación y/o desplazamiento como una forma de intercambio de individuos y grupos entre lugares. Y a la movilidad interna en tanto corredores, circuitos estructurantes de regiones, espacios, circulaciones y nuevos órdenes rurales (Rivera, 2012).

Partiendo de esto, las formas de reproducción social y producción económica en contextos de movilidad y migración, así como la diversidad socioespacial en el medio rural, nos llevan a plantear una mirada desde la complejidad de las relaciones y significados sociales de la tierra y del trabajo campesino e indígena en el totonacapan veracruzano, entendido este como territorio circulatorio que contiene el espacio, tiempo e identidad que alojan formas comunes de la vida social (Tarrius, 2000: 39-40) y en el que transitan, además de personas, bienes, dinero y servicios (Rouse, 1989). El municipio de Coyutla, el que ocupa esta investigación, forma parte del totonacapan veracruzano, una región "movediza" por su amplia tradición de movilidades y migraciones de diferentes tipos, temporalidades y objetivos (Pérez, 2018a), donde "los espacios se mueven" (Gatti y Chenaut, 1987) en función de las dinámicas regionales del desarrollo de la agricultura, la ganadería y la industria extractiva, en tiempos y espacios específicos (Ramírez, 2002; Velázquez, 1995; Chenaut, 2014). Un escenario de complejidad en el que el trabajo rural, el empleo, el ingreso y la reproducción económica se plantean constantemente en interacción,

EntreDiversidades. Revista de Ciencias Sociales y Humanidades, Vol. 9, Núm. 1 (18), enero-junio 2022. Páginas: 176-199 ISSN-e: 2007-7610. https://doi.org/10.31644/ED.V9.N1.2022.A07 
disputas y arenas de negociación personal, familiar y comunitaria, lo que repercute en los estados socioemocionales de las experiencias subjetivas culturales donde se tejen prácticas como producir, sentir, trabajar y vivir (Sennet, 2000).

Las causas que han jugado un factor determinante al motivar y alentar los procesos migratorios de los indígenas totonacas son múltiples, como las económicas y estructurales que enfrentan en sus comunidades de origen en contextos rurales descapitalizados, condiciones de pobreza y marginación. Como lo señalamos en Pérez (2018a: 194):

[...] nulas oportunidades laborales locales, falta de apoyos y recursos gubernamentales (Griego, et al., 2003). La falta de condiciones propicias de producción agrícola y comercialización han acelerado los procesos de inserción en los flujos migratorios (Moctezuma, 2008). A través del tiempo las causales de la migración se van redefiniendo y se sostienen en estructuras sociales, por lo que hombres y mujeres dan lugar a la organización informal de las redes sociales que operan en base a las relaciones de solidaridad, pertenencia y adscripción identitaria, facilitando la movilidad y el acceso a recursos escasos, pero valiosos, económicos y sociales que incrementan la incorporación de nuevos migrantes y el sostenimiento del fenómeno a través del tiempo (Massey, et al., 1987).

En la década de 1990 la migración México-Estados Unidos cobra gran importancia, sobre todo en las regiones emergentes no tradicionales. A esta se le suma la de destino mexicano hacia las zonas de desarrollo agrícola de alta tecnología-exportación de San Quintín, Sonora y Sinaloa, principalmente de jornaleros agrícolas indígenas procedentes de Oaxaca, Veracruz, Chiapas y Guerrero (Velasco, 2002). A finales de la década la migración a Estados Unidos se transforma, complejiza e intensifica, cambiando el patrón: el destino principal ahora son las ciudades, aumenta el volumen de migración indígena y esta deja de ser solo de hombres. Los migrantes indígenas mantienen lazos de pertenencia con la comunidad de origen a través de las redes familiares, de paisanaje y de organización social (Velasco, 2002). Además, las redes sociales sustentan la reproducción étnica (Arizpe, 1985), brindando dinamismo, flexibilidad, lealtad, solidaridad y ayuda mutua entre hombres y mujeres, un capital social que les protege de la vulnerabilidad y la marginalidad cuando se encuentran en la ciudad. A través de estas redes se sostienen las comunidades extraterritoriales, viven fuera pero mantienen lazos de pertenencia con la comunidad de origen (Oehmichen, 2003).

Así, lo rural se convierte en un espacio polisémico, tejido en lo dialéctico, multidimensional, entre tiempos, espacios y actores multisituados, conformado por las voces propias y las que otros han impuesto e institucionalizado y que se hallan más allá de lo dicotómico o la dupla para instaurarse en la complejidad de las interacciones sociales cara a cara o virtuales. En lo rural tienen un peso importante el uso de las tecnologías o la telefonía como mediadores de las relaciones virtuales por las que circulan emociones, nostalgias, andanzas y viajes materiales o simbólicos, entre la tierra o el espíritu como conformador de una identidad campesina redefinida constantemente por los discursos imaginarios, inventados, desarraigados, de regreso o en procesos de migración.

EntreDiversidades. Revista de Ciencias Sociales y Humanidades, Vol. 9, Núm. 1 (18), enero-junio 2022. Páginas: 176-199 ISSN-e: 2007-7610. https://doi.org/10.31644/ED.V9.N1.2022.A07 
El campo, más que un sitio homogéneo, se convierte en un espacio expandido y expansivo, una renovada cantera de imaginarios, materiales, representaciones, temporalidades y usos múltiples que conviven en la escena cultural contemporánea (De Leone, 2016: 195). De ahí la importancia de mirar lo rural desde la complejidad, como un tejido multidimensional de constituyentes heterogéneos inseparablemente asociados y atender los rasgos inquietantes de lo enredado, lo inextricable, el desorden, la ambigüedad y la incertidumbre, de ir más allá de la única realidad, a un sistema abierto no solo en equilibrio, sino en desequilibrio, renovado, compensado y de dinamismo estabilizado (Morin, 2004). La mirada sociológica en el mundo rural da cuenta de valores, actitudes y actividades sociales, relaciones reales entre personas y donde el inmigrante interpreta su nuevo ambiente social en términos de su penar habitual, idea que no tardará en ser inadecuada (Shutz, 2012a: 33). Las tipologías ya elaboradas desde el contexto del lugar de origen se desintegran en el nivel de la experiencia ambiental del contexto de llegada que no es congruente con el de sus creencias.

Por tanto, es importante comprender el medio rural no solo por sus prácticas agrícolas, relaciones económicas e interacciones con las estructuras de poder y organización social, sino también a partir de las prácticas de pertenencia e identidad, de los factores socioculturales y de las acciones cotidianas orientadas por los valores y expectativas. Se trata, por tanto, de visibilizar lo habitado por distintos actores o sujetos sociales que realizan diversas actividades de reproducción económica, ya que tradicionalmente se ha tenido la idea genérica de que en el campo viven campesinos. De ahí queremos partir, pero destacando elementos de complejidad, recurriendo a la propuesta de Bourdieu y Sayad, quienes consideran no solo que existen "auténticos campesinos", "verdaderos campesinos" o "campesinos descampesinizados", sino que incluso dan cuenta de aquellos que se definen o caracterizan a partir de su "espíritu campesino" (2017: 95-107).

Los elementos que caracterizan al "campesino" están mediados por factores personales, intersubjetivos y de relación con la tierra, en tiempos cambiantes situados en espacios que se ensanchan en lo geográfico y lo social. Así, un aspecto a considerar sería la cultura como "modelos de comportamiento y modelos de la modalidad de los comportamientos" (Bourdieu y Sayad, 2017: 116), es decir, es relevante atender el sistema de valores, normas, estilo de vida, los sentimientos y la actitud tradicional hacia el trabajo, en otras palabras, lo que se vive, se siente y se piensa como campesino. Por tanto, se trata de repensar al campesino caracterizado a partir de lo ingenuo, lo sencillo, su dignidad, la forma de alimentarse, los valores morales, la solidaridad, la manera de compartir, sus lazos sociales, la vergüenza, el sentido de comunidad, su pasión y apego por la tierra, sus tiempos e itinerarios, las actividades y relaciones con la tierra, un campesino que "honraba a la tierra y se honraba a sí mismo" (Bourdieu y Sayad, 2017).

Para el campesino la nostalgia es el verdadero motor de sus acciones (Mino, 2011: 51). La convivencia, la solidaridad y la celebración comunitaria (2011:21) son valores que han llevado consigo y ahora los adaptan a nuevos contextos sociales (Cfr. Lomnitz, 1976). Bourdieu y Sayad consideran que "todas las virtudes campesinas se resumen en la palabra niya, como la manera de ser y hacer: la inocencia, rectitud, derechura, naturalidad, ingenuidad y simplicidad" (2017: 115). De este modo, los campesinos se caracterizan por valores que excluyen la codicia, ignoran el cálculo especulativo sobre el futuro, "puesto que no aspira ni pretende limitar, ni torcer los designios de la

EntreDiversidades. Revista de Ciencias Sociales y Humanidades, Vol. 9, Núm. 1 (18), enero-junio 2022. Páginas: 176-199 ISSN-e: 2007-7610. https://doi.org/10.31644/ED.V9.N1.2022.A07 
providencia, ambición que define la malicia sacrílega” (2017: 116), pero mientras los campesinos cerrados (2017: 119) magnifican la niya, los descampesinados ven ingenuidad estúpida y santa simplicidad de los antepasados, de los viejos. Entre los buniya, una cultura casi desaparecida de la región de Cabilia, al norte de Argelia, se estima al hombre de buena fe, con intención pura, actitud de reverencia y veneración a la tierra, intimidad extrema con la tierra y las bestias, a las que jamás encara para combatir o someter. Al mismo tiempo, valoran hacer y hacerse honor, es decir, la "lealtad personal y en la buena fe", la pureza de la intención (2017: 116-119).

Todo ello conforma características, prácticas, sentidos y valores campesinos que continuamente han estado en proceso de redefinición y cambio, pero que se transforman de manera acelerada cuando se gestan las migraciones, ampliándose los espacios sociales y redefiniéndose el ser y hacer citadino, teniendo en su corporalidad un espíritu campesino de diferentes niveles de densidad. $\mathrm{Al}$ dejar su terruño, sus pertenencias materiales y tradiciones $-\mathrm{y}$ marcharse cargando consigo un equipaje simbólico y espiritual inserto en procesos migratorios de carácter internacionalalgunos campesinos cambiarán su relación con la tierra, con sus padres y con ellos mismos. La agricultura de otros tiempos ha muerto, "nuestro corazón ya no está allî" (2017: 115), expresan. Ya no hay campesinos verdaderos, afirman Bourdieu y Sayad, porque han cambiado la intención, la actitud y la conducta, al descubrir que pueden "realizarse" de otra manera. Según los autores conforman otra "humanidad", acompañada de la toma de conciencia de la condición campesina misma y de la explicitación de los postulados éticos que la fundaban (2017: 119), afirmación que aplica solo en algunos de ellos, no en su totalidad generalizada, debido a la diversidad de género, etaria y de clase de las composiciones sociales.

Ahora su ritual yace vacío de intención y contenido, sin ilusión, y desarrollan un comportamiento disociado, racional (cálculo-ganancia). Para algunos campesinos, "el abandono de la agricultura, ligado a la liquidación del espíritu campesino, se realiza secretamente y por vías indirectas" (2017: 123), la agricultura pierde así su "respetabilidad" y la tierra ya no inspira un "temor reverencial” (sagrado), sino que atraviesa un proceso donde es desvalorizada (2017: 124). Este proceso contribuye a la emigración, la descampesinización, fomentando un espíritu económico en un contexto de desplazamiento que produce desarraigo, abandono de la tierra y de los valores campesinos, lo que signfica la pérdida de su pureza en la aceleración del proceso de cambio cultural. Como se presenta en el caso de la esposa de un campesino rural mexicano, ante la decisión de migrar a la Ciudad de México y tener que abandonar su pueblo y su forma de vida, esta expresa: "esta es nuestra tierra, mira qué negra y qué suave, ¿cómo quieres que nos vayamos?” (Mino, 2011: 78). Cabe decir que estos cambios se presentan de manera gradual y diferenciada en función de las prácticas socio-laborales en que los inmigrantes estén insertos, situándose en contextos de complejidad. Las personas, lugares y momentos son evocados por medio de objetos que establecen conexiones emotivas y sociales entre los espacios, hábitat y corporalidades (Boruchoff, 1999), "objetos de interés común y de relevancia compartida con los cuales o sobre los cuales operar, de modo afectivo o potencial” (Schutz, 2012b: 46).

Para analizar lo rural como multisituado proponemos hacerlo en su relación con el fenómeno migratorio desde una perspectiva microsociológica, con el fin de captar la diversidad de causales, las redefiniciones de expectativas y los alcances de los proyectos migratorios construidos en 
procesos de interacción social (Pérez, 2001), de las experiencias reales o imaginadas (Levitt y Glick-Schiller, 2004). Se pretende comprender la migración como un proceso dinámico de conexiones e interconexiones globales, de redes sociales, prácticas y vínculos que estructuran las movilidades socioespaciales, y luego la vida laboral, social, política y cultural, tanto de la población de migrantes como de familiares, amigos y habitantes que permanecen en los contextos de salida y de llegada; donde los efectos son vistos como procesos enraizados y condicionados por múltiples estructuras sociales en las que se entretejen diferentes niveles de relaciones (Guarnizo, 2005, citado en Rivera, 2012: 31-32). Por tanto, se trata de considerar los aspectos culturales desde las construcciones imaginarias, los objetos en contextos de migración que se vinculan con procesos de cambio en las relaciones y organizaciones sociales. Los relatos, discursos, prácticas de consumo, cultura material y la transformación del espacio rural —a través de distintos tipos de construcciones, adquisición de vehículos, tierras de cultivos, nuevas viviendas o posesiones materiales - forman parte de la representación de una migración exitosa o fracasada, que se refleja e influye en las aspiraciones de las personas. Por ello, es necesario atender el ámbito subjetivo del proceso migratorio, la producción y productividad simbólica, los imaginarios — expectativas, sueños y frustraciones articulados en narraciones y discursos- que se construyen a través de mitos, canciones, historias y medios de comunicación que influyen en las interpretaciones de la realidad, los deseos, aspiraciones, miedos y desilusiones (Cruz de Echeverría, 2014: 3-4). Así, la cultura de la migración es entendida como el

[...] entramado de símbolos, significados y representaciones que se construyen en interacción en contextos sociales relacionados con el movimiento de individuos de un área geográfica a otra, [que] existe tanto de manera objetivada (artefactos) como subjetiva y performativa (valores, actitudes). Los significados que la conforman se generan en constante disputa y negociación entre los mismos migrantes, los que se quedan, los encuentros en el camino, y los distintos actores de la sociedad de acogida (Geertz, 1973; Bourdieu, 1997; Ali, 2007; Hahn \& Klute, 2007) (Cruz de Echeverría, 2014: 9).

Las subjetividades dan cuenta de los factores culturales, situándonos más allá de posiciones binarias que consideran solo a los que migran, dando también protagonismo a los que se quedan, para ahondar sobre la manera en que se ven influidos en esos múltiples y complejos ires y venires (Levitt y Glick-Schiller, 2004; Alanís y Alarcón, 2016). Desde esta perspectiva, la migración es vista como algo intrínsecamente cultural, donde la circulación de elementos tangibles e intangibles —otras ideas, símbolos y comportamientos - influye en los cambios y estímulos para la realización del viaje.

En esta cultura en movimiento como proceso integrador de las relaciones sociales juegan un papel importante las remesas sociales, recursos intercambiados en un espacio social transnacional, como lo son la estructura narrativa (ideas, valores, creencias), la convivencia comunitaria y los valores de organización social (Levitt, s/f). Levitt define las remesas sociales como un sistema de prácticas: acciones sociales moldeadas por las estructuras normativas, relaciones intrafamiliares, toma de decisiones y socialización, en las que juega un papel importante el capital social que 
se traslada junto con los migrantes y fluye con los intercambios (Levitt, 2001; Pérez, 2013). A través de ellas, además de dinero, se exportan ideas y comportamientos como normas, prácticas, identidades y capital social (Levitt, 2001). Se sostienen en sistemas de redes sociales de diversas densidades de recursos, constitución social y antigüedad (Pérez, 2013); las redes funcionan como contenedores y mantienen costumbres, lenguajes, valores, vínculos e identidades originadas en el terruño (Pérez, 2001). Pero pertenecen por la memoria, la nostalgia, las emociones, los sentimientos y la imaginación (Levitt y Glick-Schiller, 2004; Hirai, 2014; Besserer, 2013) en los procesos migratorios.

Por su parte, Rivera (2004) propone analizar la migración desde la noción de remesas socioculturales, lo que comprende la transformación de la vida, roles, relaciones y organización social y festiva. Remesas que van, vienen y circulan a manera de imágenes, narraciones, música, fotos, historias, vivencias personales y bienes materiales, ampliando el entorno social y el intercambio simbólico, y que se reflejan en el cambio de la fisonomía del pueblo en nuevas casas, negocios, antenas parabólicas, envío de dinero, paquetería, comida china o hamburguesas, cafés con acceso a internet y venta de computadoras y electrónicos. Este contexto sociocultural también se presenta en Coyutla, donde encontramos negocios emprendidos por migrantes de retorno o sus familias, los cuales aplican los saberes aprendidos en Estados Unidos, como la instalación de ciber cafés, venta de hamburguesas, envíos de dinero, transporte de mercancías locales y la circulación de objetos y artefactos alusivos a las formas de vida en Norteamérica.

De esta manera, las remesas socioculturales conforman entornos locales-globales a través de bienes y objetos personales deseados, que reflejan la relación con tierras y lugares (Boruchoff, 1999). Al regreso de los migrantes a sus contextos de origen se acentúa la distinción a través de su vestimenta, formas de hablar, bailar..., están a la moda y funcionan como elementos de posibilidad para traspasar fronteras e imponer cambios, necesidades que emergen, se vuelven masivas y se convierten en motor de importantes transformaciones sociales al interior de sus pueblos (Aquino, 2012).

\section{Las manos cosechando y los pies andando: sistema agrario y laboral regional}

El pueblo de Coyutla, la perla de la sierra, surge en el siglo XVI como parte de la estancia de Mecatlán, y en 1935 se conforma como municipio. Su nombre es un vocablo que en náhuatl significa "lugar de coyotes" y en totonaca "lugar de seis casas" (calixaxan). Se ubica en el corazón de la sierra de Papantla, en la zona norte del Estado de Veracruz. Sus principales localidades son: Las Lomas, La Chaca, El Panorama, Colonia Guadalupe, Calalco, Chicualoque y Tulapilla.

El municipio está integrado por una superficie de $234.72 \mathrm{~km}^{2}$. En 2017 tenía 22982 habitantes, de los cuales 11939 eran mujeres y 11043 hombres. En 2014, de las 6629.0 hectáreas sembradas, 5454.0 se destinaban al cultivo del maíz, 956.0 al café cereza ${ }^{2}$ y 130.0 a la naranja (GEV y SEFIPLAN, 2016). Los cultivos agrícolas predominantes son maíz, café, plátano, naranja, frijol, chile y calabaza. Además, se practica la actividad ganadera para la cría y explotación de bovino de

${ }^{2}$ El café cereza se refiere a la venta del fruto en estado óptimo de maduración, a diferencia de aquellos que lo tratan, ya sea en húmedo o en seco y lo venden en pergamino.

EntreDiversidades. Revista de Ciencias Sociales y Humanidades, Vol. 9, Núm. 1 (18), enero-junio 2022. Páginas: 176-199 ISSN-e: 2007-7610. https://doi.org/10.31644/ED.V9.N1.2022.A07 
doble propósito, ganado porcino, ovino y equino. En el caso del cultivo de la pimienta, este está parcialmente en manos de productores de origen indígena organizados en la Asociación Rural de Interés Colectivo (ARIC), que la exportan a Estados Unidos y Europa. Algunos campesinos destinan su producción al autoconsumo y otros más a la comercialización en negocios y puestos ambulantes en Coyutla.

El financiamiento para la producción de las parcelas proviene de diversas fuentes, como la venta de sus productos, las remesas que envían los familiares desde Estados Unidos y los créditos que se obtienen a nivel local a través de empresas privadas como Compartamos-Banco, instituciones gubernamentales y prestamistas particulares. Los campesinos de Coyutla tienen diferentes tipos de relación con la tierra, son pequeños propietarios, arrendatarios y/o medieros, y hay quienes no la poseen, ante las condiciones económicas y sociales de la región. Las realidades cambiantes que enfrentan en su vida cotidiana muestran que sus sueńos están ligados a la tierra, a pesar de que muchos de ellos no cuentan con ella, pero el hecho de trabajarla, aun cuando sea rentada, prestada o a medias, alimenta su deseo de hacer siempre una buena siembra para obtener un "maíz bonito".

La dinámica demográfica de los municipios de la sierra papanteca muestra que "el caso de Coyutla presenta un crecimiento entre 1990 y 2000, pero hay una pérdida de población para 2005, misma que se recupera en 2010 para quedar casi como en 2000. En Espinal vemos un crecimiento positivo entre 1990 y 2010, pero mínimas fluctuaciones que pueden deberse a los movimientos migratorios de sus pobladores" (Pérez, 2018b: 198). Filomeno Mata mantiene un crecimiento poblacional constante, pero mínimo al igual que el municipio de Mecatlán.

La vida cotidiana de los coyutecos, al igual que la de muchos otros campesinos hablantes de lenguas indígenas en el país, está ligada de diversas formas a la lógica de mercado, a los factores externos que han permeado sus relaciones más íntimas: radio, televisión, internet, computadoras y uso de celulares (Chenaut, 2014), adquisición y uso de cosméticos, revistas, ropa, música y telenovelas (García, 2014), uso de tiempo libre, tecnologías, redes sociales como Facebook y aplicaciones como WhatsApp (Pérez, 2016), que contribuyen a cuestionar la relación con el respeto, los valores y el ser indígena de otros momentos. Se perciben transformaciones en la percepción y en la práctica en torno al trabajo fuera de la comunidad, en la educación, la sexualidad, el matrimonio, el baile e incluso en el noviazgo, los cuales se resignifican y adquieren particularidades dependiendo de la edad, el género y la movilidad. Un ejemplo de ello es la figura del xinula o indio revestido, quien muestra elementos redefinidos de sus tradiciones, transformando su identidad al migrar y manteniendo una actitud creativa ante los cambios que le toca vivir mediante la reconfiguración de relaciones y prácticas para adaptarse a otros valores y formas de pensar distintas a las indígenas y mestizas y que son más propias de los contextos urbanos a los que migran. De esta forma, algunos de los cambios que se han ido configurando con el paso del tiempo en la región son: diversificación de la oferta educativa y acceso a la escuela, que influye en que dejen de hablar en totonaco y aprendan el espańol, así como en que se abandone cada vez más la vestimenta tradicional de manta e intensos colores; mayores niveles de escolaridad; la edad para formar pareja u hogar se modifica y deja de ser a los 12 o 13 ańos; las normas que rigen la conducta familiar son estrictas, los padres ejercen poder y control

EntreDiversidades. Revista de Ciencias Sociales y Humanidades, Vol. 9, Núm. 1 (18), enero-junio 2022. Páginas: 176-199 ISSN-e: 2007-7610. https://doi.org/10.31644/ED.V9.N1.2022.A07 
y sancionan moralmente, por ello algunos migran en busca de libertad, el ejercicio de la sexualidad y la toma de decisiones (Aquino, 2012; Chenaut, 2014; Muñoz, 2004).

Así, nuevas identidades en Coyutla se han incorporado de manera crítica, rechazando, cuestionando prácticas y representaciones (Chenaut, 2014: 145), porque las tradiciones cambian continuamente, en ocasiones de manera acelerada, produciendo tensiones por reproducción de valores y dinámicas sociales ligadas a la vida comunitaria y cultural.

La identidad indígena de los coyutecos se sustenta en su historia, la relación con la tierra, el trabajo agrícola, los procesos de organización social, su sentido de pertenencia, lazos de solidaridad, la mano vuelta o faena comunitaria y su lengua y prácticas culturales como las danzas y la música (Muñoz, 2004; Chenaut, 2014), en constante proceso de transformación en un contexto de marginalidad, analfabetismo, altos niveles de pobreza y monolingüismo.

Los procesos históricos de los coyutecos en relación con la propiedad y tenencia de la tierra, dejan ver su acceso limitado no solo por los aspectos económicos sino también por los sociales y políticos que ejercen un importante poder y control, como en los sistemas de hacienda, cacicazgo y la ganadería extensiva. Por ello, la lucha por el acceso a la tierra, la justicia y los derechos humanos ha sido parte central de las demandas y la acción cotidiana de los coyutecos. La movilización indígena como producto del descontento social ha tenido gran fuerza representada y consensada en tres organizaciones: Tres Corazones, ARIC (Asociación Rural de Interés Colectivo) y Movimiento Ciudadano Coyuteco, que han luchado y luchan contra la opresión, el despojo y la marginación a través de la evangelización integral, los catequistas y la educación popular para fortalecer su cultura, identidad, pertenencia y arraigo a la tierra (Muńoz, 2004). Aunado a ello, una de las formas en que los coyutecos construyen su identidad es a través de las relaciones de compadrazgo, favores, lealtad política y reciprocidad entre mestizos e indígenas, ligados a partidos políticos como el PRI y el PRD (Chenaut, 2014). De esta forma, se alimenta y recrea la lucha por la autonomía en base a principios y valores indígenas, considerando la pluralidad de identidades, de organización social, productiva y religiosa (Muñoz, 2004).

En la región, los años ochenta del siglo XX se caracterizaron por el desarrollo de importantes procesos de organización social regional en los municipios de Coahuitlán, Coxquihui, Coyutla, Chumatlán, Filomeno, Mecatlán y Zozocolco, vinculados todos a la producción agrícola. En 1980 se creó la ARIC de Coyutla, que se dedicaba básicamente a la exportación de pimienta, y en 1984 se configuró la Sociedad Cooperativa Agropecuaria Forestal e Industrial. Ambas trajeron beneficios considerables a nivel organizativo, social y económico para los productores campesinos e indígenas de Coyutla y Filomeno Mata (Muñoz, 2004).

Las relaciones políticas de la población totonaca con el gobierno a finales de los ochenta y principios de los noventa configuraron procesos locales que permitieron conectar con lo regional y lo nacional a partir del interés local e interés del exterior: acceso a tecnología, al mercado, créditos y sistemas de trabajo. Las políticas indigenistas oficiales fueron impuestas a través del Programa Nacional de Solidaridad o bien apropiadas mediante mecanismos de adecuación en la que los totonacos plantearon proyectos propios y reorganizaron su actividad política, productiva y ceremonial y su patrimonio cultural (Ramírez, 1994: 242).

EntreDiversidades. Revista de Ciencias Sociales y Humanidades, Vol. 9, Núm. 1 (18), enero-junio 2022. Páginas: 176-199 ISSN-e: 2007-7610. https://doi.org/10.31644/ED.V9.N1.2022.A07 
Mediante comités comunitarios de planeación y fondos regionales de solidaridad se desarrollaron proyectos estratégicos que generaron derrame económico en la región, beneficios sociales, mejoraron la producción, consolidaron organizaciones y evitaron la migración, y que a su vez trajeron consigo formas socioculturales emergentes de organización social que respondían a nuevos estilos de gobernanza, políticas modernizadoras de proyectos, dialécticas de lo impuesto y lo apropiado, reorganización productiva de los totonacos, democracia local con reglas y valores que le son propios y reglas de apropiación, acuerdos y consensos de la comunidad (1994: 253-255).

Un hecho significativo para el desarrollo de la región de la sierra papanteca fue la construcción y mejora de infraestructura de la carretera, en 1969 la que cubría el tramo Papantla-Poza Rica y en 1985 la de Mecatlán-Coyutla-Papantla, lo que facilitó la movilidad de la población, la venta de fuerza de trabajo en una región más amplia, así como participar de diversas actividades productivas y educativas y entrar en contacto con otras formas culturales. En concreto, la mejora de la infraestructura local con la construcción de la carretera en la región en la década de los ochenta facilitó las interacciones sociales y amplió las rutas comerciales y de movilidad de la producción agrícola y petrolera con los municipios ubicados en la llanura costera -Cazones, Espinal, Gutiérrez Zamora, Papantla, Poza Rica, Tecolutla y Tihuatlán- donde se cultivaba cítricos, maíz, chile, plátano, frijol, tabaco, vainilla, coco y ajonjolí y se practicaba la ganadería bovina. Los indígenas de tierras adentro - la sierra de Papantla - acudían para ofrecer su fuerza de trabajo, tanto en las actividades para las cuales habían desarrollado habilidades como para aquellas más novedosas ligadas a la industria del petróleo o de servicios, las cuales les permitía obtener mejoras materiales, educativas y económicas para sus familias.

Así, la región de la sierra pasó de las dinámicas de movilidad por los circuitos comerciales y la arriería a la de la venta de fuerza de trabajo facilitada por la construcción de carreteras y caminos (Velázquez, 1995), y las dinámicas comerciales de Coyutla se vincularon a las ciudades de la costa, diversificando actividades, fuentes de ingreso, habilidades y formas de venta de fuerza de trabajo (Chenaut, 2014). Los hombres dejaron de lado el traje indígena de manta y se incorporaron al comercio informal en las ciudades, donde hasta hoy en día se observan otras dinámicas como la comercialización de las danzas, productos culturales que con la llegada del turismo contribuyen a la resignificación del contenido simbólico de los objetos culturales.

La producción agrícola en las llanuras costeras fue muy dinámica y compleja a lo largo del siglo XX. Pasaron de un cultivo a otro en un quinquenio o una década, lo que facilitó la movilidad no solo de personas sino también de conocimientos, productos, dinero y expectativas. Cultivaron la vainilla y el plátano, que después exportaron a Europa y Estados Unidos, para posteriormente perder toda importancia. También cítricos y tabaco, para luego introducir ganado y chile. El maíz sustituyó al tabaco, y más tarde la naranja al plátano en una dinámica económica de gran derrama para los capitalistas, no así para los jornaleros y la peonada. Los yacimientos de petróleo que se ubicaban solo en algunos poblados de la llanura costera se empezaron a explotar, dañando a la sociedad, las tradiciones, los cultivos y los pocos caminos y escasas carreteras de la región (Ramírez, 2002). Se trata, por tanto, de una etapa con una compleja dinámica en los sistemas 
de producción agrícola, con altas y bajas, con vaivenes en el mercado y en las ofertas laborales, con épocas de grandes ingresos pero también de pobreza y escasez para los habitantes indígenas (Velázquez, 1995).

Para mediados del siglo XX la gran demanda de mano de obra llevó a los totonacos a la naciente metrópolis de Poza Rica, al sector de los servicios (Mendoza, 2014; Vera, 2014). Con el tiempo y las reestructuraciones del mercado laboral las rutas se fueron ampliando hasta que llegaron y se establecieron en la Ciudad de México, luego fueron a Tlaxcala y Monterrey debido al trabajo en la construcción y el servicio doméstico (Moctezuma, 2008), a diversas ciudades de la frontera norte, a los Estados Unidos (Chenaut, 2010) y, desde 2009, de la comunidad de Calalco a Canadá, conformando así un sistema migratorio complejo transnacional (Pérez, 2018), donde los seres humanos se convierten en mercancías y recientemente transitan de un lugar a otro de manera constante, como si se encontraran "en el limbo" (Bauman, 2008).

Así, mientras que a principios del siglo en la región se exportaban productos del campo (Ramírez, 2002), hoy se exportan trabajadores, de la misma manera que sucedió en el sector del café en el centro de Veracruz desde la década de los noventa. El desplazamiento por lugares distintos, múltiples y cambiantes resulta interesante, pues a diferencia de las migraciones internacionales tradicionales, los totonacos no crean "comunidades hijas" establecidas en un solo lugar de destino (Alarcón, 1988), sino más bien devienen en nómadas laborales (Aquino, 2012), teniendo que cubrir otros costos, riesgos, sueños y proyectos en el proceso de intensa movilidad o errancia.

Las relaciones que los totonacos habían tenido y alimentado con la tierra y las actividades agrícolas se han transformado constantemente y complejizado recientemente con las nuevas generaciones. Así, encontramos percepciones y consideraciones que pudieran parecer de pronto contradictorias, pero que más bien reflejan la diversidad de formas de pensar y conducirse de sus actores; redefiniciones que se han producido en parte por la participación en las distintas dinámicas migratorias, influidas por los efectos subjetivos de la llegada e inversión de remesas económicas y por la redefinición de sus expectativas respecto al sostenimiento de la agricultura.

Históricamente, la sierra de Papantla ha tenido un dinamismo importante de movilidad de personas y recursos tangibles e intangibles. Hasta los años ochenta del siglo pasado los circuitos comerciales se mantuvieron entre el totonacapan y la sierra norte de Puebla, pero a partir de la puesta en funcionamiento de la carretera los habitantes de los municipios de Filomeno Mata, Mecatlán y Coyutla pudieron salir de manera más rápida y accesible hacia Papantla y Poza Rica, y llegar a la ciudad de Puebla y Ciudad de México. Con el transcurso del tiempo, cada vez más, tanto hombres como mujeres, se insertaron en los mercados de trabajo rural y urbanos temporales, conformando también una migración permanente y establecida en la Ciudad de México.

A diferencia de otros migrantes rurales del sureste del país, los totonacos no formaron parte de quienes vendían su fuerza de trabajo en los campos agrícolas del noreste, en Sonora y Sinaloa, sino que de manera acelerada se conformaron circuitos migratorios con destino a la Ciudad de México, Monterrey, la frontera norte, Estados Unidos y Canadá.

Esta diversidad de destinos no tradicionales, la participación de las mujeres en los flujos, los destinos urbanos en la costa Este, la movilidad por diversos estados de la Unión Americana,

EntreDiversidades. Revista de Ciencias Sociales y Humanidades, Vol. 9, Núm. 1 (18), enero-junio 2022. Páginas: 176-199 ISSN-e: 2007-7610. https://doi.org/10.31644/ED.V9.N1.2022.A07 
actividades laborales en el sector servicios y la obtención de ingresos económicos muy por arriba de lo que obtenían en sus comunidades de origen dan un característica particular a la migración internacional de los totonacos.

Algunos coyutecos consideran que la agricultura regional y local se ha visto afectada por la pérdida o circulación de la población, al repercutir en la transformación de los valores culturales hacia la tierra, la milpa, el trabajo comunal, la solidaridad, el dinero y las relaciones sociales indígenas (Muñoz y Casados, 2008). En el caso de la migración nacional se percibe que esta provoca en algunos casos el abandono de la tierra y que la ausencia de hombres conlleva el trabajo de la tierra "a medias" o la necesidad de contratación de trabajadores venidos de diversas geografías. Además, hay un cierto desinterés por algunos sucesores o jóvenes en seguirla cultivando porque no es redituable a nivel económico.

Existe la percepción diferencial de que los migrantes internacionales y sus familias no solo incrementan su capital económico, sino también el cultural, lo que se refleja en la incorporación de prácticas agrícolas y el destino que le asignan a la producción: algunos invierten las remesas económicas en el campo, en la compra de tierras, maquinaria, agroquímicos y semillas mejoradas (Gil, 2012), así como en ganado bovino o contratación de peones, elevando los niveles de productividad, por lo que una parte importante de la cosecha se destina a su comercialización a nivel local y regional, a las grandes ciudades o metrópolis. Los campesinos que migran a Estados Unidos hacen importantes inversiones en la compra de tierras para el cultivo, de manera que con el tiempo redefinen el proyecto migratorio en mejores condiciones materiales de reproducción social y económica.

La migración a Estados Unidos presenta una diferencia importante respecto de la nacional, sobre todo en en términos del nivel de ingreso, que se refleja en la inversión y adquisición de bienes materiales - hay quienes compran tierras y terrenos de uso agrícola y otros que adquieren solares para la edificación de casas y quienes invierten en la modificación y ampliación de las viviendas - Una cuestión paradójica que identificamos es que en un primer momento se practica la venta o empeño de tierras para financiar la migración a Estados Unidos, pero después con las remesas se adquieren solares o parcelas para el cultivo y la producción, una práctica donde los factores económicos no son los únicos determinantes, sino que se hace también por el valor simbólico de la tierra, la tradición del cultivar y el arraigo (Gil, 2012; Nava, 2010). Por tanto, primero la tierra financia la migración y luego la migración sostiene la tierra, pero no de manera dicotómica, sino en un proceso complejo donde parece que se mantienen los valores campesinos y la relación con la tierra pero desde una racionalidad económica estadounidense del trabajo.

La cultura local refleja las diversas formas de pensar ante los cambios producidos por diversos factores, que se aceleran por la presencia de los procesos migratorios. Llama la atención la diferencia generacional en la idea del trabajo y de la relación con la tierra: para la gente de la tercera edad y los adultos tiene un valor importante, más simbólico que económico, se trata del peso de la herencia y el arraigo, mientras que a los jóvenes no les interesa conservarla, adquirirla o trabajarla debido a que su objetivo es obtener una ganancia económica que nunca ven y por ello no forma parte de sus expectativas, por lo que algunos la abandonan en corto tiempo. Se han transformado los valores campesinos.

EntreDiversidades. Revista de Ciencias Sociales y Humanidades, Vol. 9, Núm. 1 (18), enero-junio 2022. Páginas: 176-199 ISSN-e: 2007-7610. https://doi.org/10.31644/ED.V9.N1.2022.A07 
Las autoridades locales, quienes ostentan un cargo comunitario, las personas de respeto y de trabajo o los jefes de hogar consideran y expresan con lamento el hecho de que los jóvenes a pesar de haber nacido en esta tierra no le tengan amor y la abandonen sin darse la oportunidad de trabajarla y arraigarse a ella, y el que muchos prefieran buscar el futuro de sus vidas en la migración; como dirían Bourdieu y Sayad: "Poco a poco todo el mundo se ha ido olvidando que existe el trabajo de la tierra” (2017: 105). Este es un fenómeno que en este periodo de globalización y de políticas neoliberales es más o menos generalizado en el campo mexicano.

En las últimas dos décadas, a raíz del aumento masivo de la migración a Estados Unidos, ha cambiado el valor que se le asigna al dinero, y el gasto conspicuo influye de manera determinante en las expectativas juveniles que ubican el futuro y el progreso económico y social en otro lugar, en el que realizan actividades menos arduas y pesadas y mejor pagadas en el sector servicios, el comercio o la industria de la construcción, siempre fuera de la cabecera municipal. Cabe decir que no siempre se logran cumplir las expectativas que se formularon al migrar, debido a que la realidad supera sus alcances, ya que las condiciones materiales de vida y de reproducción social implican dinámicas inesperadas que para algunos no son fáciles de alcanzar.

\section{Las dinámicas migratorias entre Coyutla y Estados Unidos}

La cabecera municipal de Coyutla funciona a manera de nodo reticular organizador y aglutinador de importantes actividades políticas, económicas, religiosas y socioculturales. Es un punto geográfico con gran dinamismo regional, nacional e internacional debido a la gran cantidad y diversidad de interacciones que ahí confluyen. Los espacios comerciales, el tianguis semanal, el arribo de la población proveniente de diversas localidades para vender o comprar alimentos, adquirir insumos para la producción agrícola, ropa o enseres domésticos y una agricultura de bajos ingresos ligada al cultivo del maíz y el café confluyen generando flujos de movilidad constantes y permanentes de diversos actores hacia adentro y hacia fuera del municipio y la región serrana.

A la cabecera municipal de Coyutla arriban recurrentemente hombres y mujeres para vender su fuerza de trabajo por periodos diversos de días, semanas o durante la cosecha, provenientes de Arenal, Panorama, Cerro Grande, Filomeno Mata, La Chaca, Calalco, Mecatlán, Entabladero y Rancho Alegre, pertenecientes a los municipios de la sierra de Papantla - Espinal, Mecatlán, Filomeno Mata y Coyutla- También llegan de los estados de México y Puebla. Las actividades que a nivel local realizan las mujeres que provienen de otras comunidades son el empleo doméstico, el comercio y el sector servicios. Los hombres se desempeñan en el campo, en el sector de la construcción y en el transporte. La mayoría de las mujeres en 2012 ganaba 100 pesos por día, mientras otros obtenían 80 empleándose en tiendas y negocios, y una parte menor, quizás los más calificados como encargados y capataces de campo o maestros albañiles, 120 pesos.

Las movilidades y migraciones forman parte del paisaje productivo y de reproducción socioeconómica en la región. Los hombres y mujeres que salen de Coyutla en busca de fuentes de empleo asalariadas en actividades agrícolas y de servicios se dirigen a la ciudad de Papantla debido a que tiene una economía diversificada, dinámica y ofrece una mayor oferta de trabajo. Otros van a la cercana comunidad de Entabladero y Filomeno Mata, Arenal, Espinal y Calalco, donde

EntreDiversidades. Revista de Ciencias Sociales y Humanidades, Vol. 9, Núm. 1 (18), enero-junio 2022. Páginas: 176-199 ISSN-e: 2007-7610. https://doi.org/10.31644/ED.V9.N1.2022.A07 
se emplean en los servicios y labores agrícolas. Hay quienes se dirigen a áreas urbanas la llanura costera de la región, como Poza Rica y Coahuitlán, donde las economías regionales ligadas a la industria del petróleo y los servicios ofertan mejores salarios y más opciones laborales. También, se encuentran los que migran de manera definitiva, o por largos periodos y largas distancias a las ciudades de México, Monterrey y Puebla, así como a las plataformas petroleras en el estado de Campeche (Moctezuma, 2008) y a las ciudades ubicadas en la frontera norte donde se emplean en la industria maquiladora (Pérez, 2018).

La elección de los lugares a los que emigran no es totalmente aleatoria o circunstancial, pues se dirigen a centros de población que son nodos geográficos clave en sus tejidos de interacciones sociales, por lo que hacen uso de su capital social para insertarse de manera más fácil a los mercados de trabajo, por invitación o recomendación. Llama la atención que algunos consideran que hay coyutecos que migran o se desplazan geográficamente aun cuando no saben a dónde ir, o no tienen un conocido o familiar que los oriente o ayude. Se van por cuenta propia, a la aventura, y dejando a su suerte el riesgo de conseguir o no un empleo o un lugar donde alojarse. Hemos identificado vínculos con diferentes niveles de densidad, y redes sociales y de paisanaje que proveen diversos recursos para el acto migratorio; la solidaridad contribuye a cohesionar los lazos que los sostienen. Un factor importante que influye en las movilidades laborales es el capital humano y social con que cuentan o del que pueden hacer uso los coyutecos para acceder a información valiosa sobre ofertas u oportunidades de empleo, dónde ofrecen mejores salarios y la existencia de vacantes con ciertos patrones o empresas en condiciones más apremiantes.

La percepción sobre quiénes deben participar o no en los espacios públicos o privados, en la casa o el trabajo, es parte de la ideología tradicional campesina y de los valores indígenas, y diferenciada en parte por el género, la edad, la etnia, entre otros. Una idea constante entre algunos coyutecos entrevistados es que es más común que quien migre y salga del pueblo en busca de trabajo sea el hombre, porque son los que enfrentan el peligro, los responsables de la manutención, los proveedores, porque son "más fuertes” y es más fácil que consigan trabajo. Esta perspectiva se complementa con la de quienes consideran que la mujer debe quedarse en casa, cuidar a los hijos, y que no es fácil que consiga trabajo porque es motivo de discriminación o porque está asignada a roles dentro del hogar, al espacio de lo privado. Pero esa es solo la voz de algunos coyutecos, pues en realidad hay mujeres de la comunidad que han migrado tanto a Estados Unidos como a la frontera norte donde se emplean en las maquilas.

En lo referente a la migración internacional coyuteca encontramos que las causas de la migración a Estados Unidos son: falta de empleo, la precaria situación económica, los salarios bajos, por necesidad, que "el dinero no alcanza", que a nivel local no hay dinero ni trabajo; o bien el deseo de tener un mejor ingreso para hacer su casa, vivir mejor, y manifestaron también el haber migrado porque los invitaron. Por su parte, en cuanto a los motivos que impulsan a migrar se identificaron los de obtener un mejor ingreso y acceder al trabajo asalariado, cumplir sus expectativas y sueños y, en menor medida, el deseo de aventura. Los proyectos migratorios se definen de manera individual y familiar dependiendo de los objetivos y metas que se pretendan alcanzar, de ahí su duración mayormente entre 2 y 11 años. Además, la cantidad de años de estancia en Estados Unidos también se establece por factores como la dificultad en el acceso

EntreDiversidades. Revista de Ciencias Sociales y Humanidades, Vol. 9, Núm. 1 (18), enero-junio 2022. Páginas: 176-199 ISSN-e: 2007-7610. https://doi.org/10.31644/ED.V9.N1.2022.A07 
al mercado de trabajo, el nivel de ingreso que tienen, el acceso a bienes materiales en poco tiempo para entonces poder volver a casa, así como las presiones personales y emocionales que experimentan al estar alejados y distantes de sus familias.

Las interacciones sociales y las diversas maneras de mantener los vínculos familiares entre el lugar de origen y el de destino se establece mediante el regreso de los coyutecos a la comunidad y haciendo uso del teléfono doméstico y vía celular - la recurrencia en las llamadas es principalmente cada 8 y 15 días-.

Respecto de los efectos o cambios que la migración internacional trae a las familias y sus integrantes en la comunidad, estos presentan ciertos sesgos enfatizados por la diferencia de género, etnia, clase y edad, pues hay quienes consideran que los más evidentes son el abandono de los hijos y la esposa y su repercusión en los estados afectivos y emocionales - efectos en la recomposición del núcleo familiar por los años de ausencia, vivir con el sentimiento de nostalgia por extrañar al ser querido, las preocupaciones respecto al estado de salud, la infidelidad conyugal-.

Se percibe que si bien los jóvenes migrantes contribuyen y ayudan al desarrollo de la comunidad con el envío de remesas, hay una pérdida en las prácticas laborales y de los oficios tradicionales que dejan de reproducirse, disminuyendo su importancia social. Algunos investigadores como García (2014) identifican una transformación de tradiciones y valores, así como despoblamiento del lugar: se abandona el campo y a su regreso los jóvenes traen consigo hábitos de consumo de alcohol y se ven envueltos en actos públicos que rompen el orden comunitario tradicional. Coincidimos parcialmente con estas aseveraciones, en la medida en que los procesos migratorios, si bien han acelerado cambios, también han traído nuevas dinámicas en el consumo de sustancias, las formas de ocio y el uso del tiempo libre, debido a las relaciones sociales y económicas desarrolladas en los lugares de destino, las cuales les permite tener ingresos mayores que los que se obtienen localmente.

La migración de Coyutla a Estados Unidos ha tenido varias etapas de desarrollo. Sus inicios datan de los años sesenta, aunque se alcanza un mayor desarrollo en los noventa, paralelamente al aumento de las migraciones en varias regiones de Veracruz, ligadas a la desaparición del Instituto Mexicano del Café (INMECAFÉ) y la caída del precio de la gramínea en 1988 (Pérez, 2018). Los estados de destino entre 1962 y 1990 fueron los tradicionales de la migración México-Estados Unidos - Texas, Illinois y California - y "los denominados emergentes" — Arizona, Atlanta, Carolina del Norte, Florida, Nueva York y Luisiana-.

A pesar de que los coyutecos identifican la migración como parte de sus vidas, ya que la mayoría tienen algún familiar o conocido que se ha ido, desconocen los lugares en los que se encuentran. De manera general, dicen que van a Estados Unidos o al norte, pero no identifican claramente la ubicación o geografía específica de destino, ignoran las actividades a las que se dedican y, por lo regular, cómo es su forma de vida. Según nuestros datos obtenidos en trabajo de campo, en 2012 los coyutecos migrantes fueron a Alabama, Atlanta, California, Carolina del Norte, Illinois, Florida, Texas, Kansas City, Luisiana, Michigan, Nueva York, Oregón y Virginia. Además, desde 2009 se presentó y desarrolló la migración temporal y por contrato a Canadá. De hecho, los lugares de destino a los que se suelen dirigir se definen a partir de la red social de la

EntreDiversidades. Revista de Ciencias Sociales y Humanidades, Vol. 9, Núm. 1 (18), enero-junio 2022. Páginas: 176-199 ISSN-e: 2007-7610. https://doi.org/10.31644/ED.V9.N1.2022.A07 
cual reciben recursos para su migración, incluso algunos de ellos conocen a donde irán solo en los últimos momentos antes de iniciar el viaje.

El cobro de las remesas económicas que los esposos e hijos envían desde Estados Unidos se hace mediante Telégrafos de México, Elektra, Sigue Global Money Transfer en algún banco ubicado en Coyutla, Papantla o Poza Rica o en centros de cambio local. La forma de ejercerlas es decidida por los propios migrantes, por la esposa y la familia. Prevalece la idea de que ese dinero se emplea principalmente en los rubros de salud, educación y alimentación, en la adquisición de vehículos y mejora de la vivienda y en la contratación de mano de obra para el mantenimiento productivo de la parcela. Las remesas económicas han sido de gran importancia para capitalizar las condiciones familiares de reproducción a través de la adquisición de parcelas o solares, ya que solo una pequeña parte de campesinos es propietaria de tierras de uso agrícola.

\section{Cambio cultural y socioemocional en un contexto de migración internacional}

La migración internacional que se presentó de manera acelerada, heterogénea y novedosa sustentada en vínculos sociales, redes familiares y de paisanaje, la circulación del capital social, la solidaridad, ayuda y reciprocidad que contenía los elementos de identidad y pertenencia de los totonacos, pero con variantes prácticas y cambiantes de acuerdo a los contextos transnacionales en que tenían lugar.

La migración de los jefes de hogar y su ausencia por periodos y distancias largas tiene repercusiones importantes en las dinámicas, roles e interacciones sociales del grupo doméstico. En el caso de las esposas de migrantes, las problemáticas que experimentan se presentan cuando deben trasladar su residencia a la casa de los suegros o de sus padres y deben alejarse de las opiniones que intentan influir en su independencia, en la forma de conducirse socialmente y en la manera de ejercer el gasto y distribuir las remesas económicas. Las mujeres se enfrentan a un aumento y diversificación de cargas de trabajo y responsabilidades al hacerse cargo de construir o modificar la casa, contratar albañiles o peones y supervisar el trabajo en la parcela, asistir a reuniones en el pleno del ejido, educar a los hijos y asumir roles que antes tenía el esposo.

Si el hombre se desobliga como proveedor o envía poco dinero — por bajo ingreso, falta de trabajo o porque tiene una nueva pareja en Estados Unidos - la esposa tiene que buscar las formas de hacerse de un ingreso vendiendo su fuerza de trabajo en el sector servicios - como empleada doméstica, elaborando productos alimenticios para su venta o llevando al mercado un poco de la producción agrícola propia-. Respecto a la ausencia del esposo, incluso hay quienes consideran que las mujeres tienen que trabajar por él, hacer lo que a él le correspondía, ser proveedora y asumir el rol de jefa de hogar.

Algunas veces, las mujeres no saben cómo está el marido y su ausencia les preocupa. Otras, los esposos son celosos, pelean y las regańan por teléfono. Dońa María dijo: "me sentí sola, triste y me tenía que llamar a diario, por eso mejor se regresó” (Pérez, 2012a, entrevista a María, Coyutla, Veracruz).

Los coyutecos tienen claro que hay una alta circulación de personas que regresan de Estados Unidos, sea por decisión propia al haber cumplido con los objetivos de su proyecto migratorio, de manera temporal, de visita o definitivamente. En algunas ocasiones regresan de manera forzada

EntreDiversidades. Revista de Ciencias Sociales y Humanidades, Vol. 9, Núm. 1 (18), enero-junio 2022. Páginas: 176-199 ISSN-e: 2007-7610. https://doi.org/10.31644/ED.V9.N1.2022.A07 
al haber sido deportados, o bien debido al aburrimiento que sienten al estar lejos de la familia y extrańarla, o porque se acabó la temporada u oportunidades de trabajo, situaciones que se han agudizado y convertido en una constante desde 2008, con la crisis económica e inmobiliaria en Estados Unidos.

Los cambios de las formas de ser y actuar de los migrantes de retorno se dejan ver claramente al mirar sus cuerpos y vestimentas. Ahora son la otredad, ajenos al paisaje social y cultural local. Los coyutecos perciben que regresan con nuevas costumbres que resultan alentadoras para que otros quieran irse a Estados Unidos a trabajar, traer dinero y comprarse casa, camioneta o tierras. Traen consigo prácticas que llevan a cabo con la familia y amigos, reflejando un estatus de superioridad. Celebran reuniones y fiestas donde el menú difiere del tradicional — carnes asadas, "wings" (alas de pollo fritas)—, festejan Halloween o, como dicen los hombres de mayor edad, "ahora nomás dicen 'soda' e imitan a los de razón [mestizos]". Todos estos elementos forman parte de "la reinserción sociocultural como el proceso donde el migrante reconstruye los referentes simbólicos de los repertorios culturales que lo vinculan o separan de la colectividad de pertenencia una vez que regresa” (Nicolás, 2019: 319).

Expresan que los jóvenes que vienen del norte ahora "se visten como cholos, traen tatuajes, pantalón guango, andan pelones, escuchan música 'rara' [hip hop] y norteña, son como entre cholos y vaqueros, cuando andan borrachos son presumidos, hasta hablan inglés y usan palabras que se escuchan extrañas, antes no salían del rancho, ahora se van por muchos lados a andar" (Pérez, 2012b, entrevista a Juan Martínez, Coyutla, Veracruz). Son "un nuevo tipo de hombre que se deja definir negativamente, por lo que ya no son y por lo que no son todavía: campesinos descampesinados, seres que se destruyen a sí mismos" (Bourdieu y Sayad, 2017: 199). Por tanto, "se percibe un ajuste social de sus experiencias significativas en un campo de aventura, en situación problemática y difícil de dominar, [...] [y el migrante se convierte en] un 'hombre marginal', un híbrido cultural que vacila entre dos pautas diferentes de vida grupal, sin saber a cuál de ellas pertenece" (Schutz, 2012a: 41).

El pueblo de Coyutla se presenta como un escenario de disputas socio-culturales al confrontarse e interactuar costumbres locales y aquellas ajenas traídas de fuera, entre los que se quedaron en el espacio de sus raíces y los que salieron de su contexto local-regional y ahora se vuelven diferentes, "les da pena vestir sencillo y quieren usar solo ropa a la moda, de marca y mezclilla" (Pérez, 2012c, entrevista a Enrique López, Coyutla, Veracruz): "si se van es para luchar no para aprender cosas malas", dice un viejo con tristeza (Pérez, 2012d, entrevista a Manuel, Coyutla, Veracruz). Como apunta Sennet: "El campesino que todos llevamos dentro lucha contra la capacidad de arruinarse a sí mismo" (2000: 106). Las transformaciones referidas se relacionan directamente con la población migrante, pero quienes se quedan también cambian, al acceder al trabajo en el sector servicios, a la educación o al uso de la tecnología, o al consumir diferentes tipos de música, nuevas vestimentas y accesorios de belleza traídos de contextos externos.

Los procesos migratorios de Coyutla a Estados Unidos motivados por la búsqueda de mejores condiciones de vida familiar tienen implicaciones sociales y culturales tanto para quienes se van como para los que se quedan. Son dinámicas de movilidad que se sustentan en interacciones de intersubjetividad donde las acciones en ocasiones están influidas por los los

EntreDiversidades. Revista de Ciencias Sociales y Humanidades, Vol. 9, Núm. 1 (18), enero-junio 2022. Páginas: 176-199 ISSN-e: 2007-7610. https://doi.org/10.31644/ED.V9.N1.2022.A07 
objetos y la información que circula entre ambos países, como bien lo señala nuestro informante: "Llegan contando buenas cosas de allá y la gente se emociona, los quieren imitar, les cuentan muchas cosas, por eso también se van" (Pérez, 2012e, entrevista a Nemesio, Coyutla, Veracruz). La experiencia de migración entre los coyuqueños forma parte de su vida cotidiana contribuyendo a la redefinición de sus prácticas laborales y culturales, esperamos haber aportado los elementos precisos para comprender las formas de hacer sociedad en el medio rural actual.

\section{Conclusiones}

Las dinámicas complejas de interacción social y producción económica en contextos de movilidad geográfica que tienen lugar en Coyutla, Veracruz, se gestan a partir de diversas causales, estructuras sociales que sostienen las migraciones de carácter laboral reduciendo costos y riesgos a través del tiempo. Se identificaron múltiples tipos de movilidad entre geografías donde los coyutecos nacen, se reproducen, estudian, aprenden, trabajan, venden su producción agrícola y se divierten, contextos rurales con la impronta de las otredades regionales y globales que redefinen sus procesos cotidianos de reproducción socioeconomica y cultural.

Las relaciones con la tierra, el trabajo en el campo y el arraigo a la tradición y valores locales presentan cambios importantes para las nuevas generaciones, que se constituyen con valores globales, migratorios y expectativas que se cubren fuera del contexto local, y que han elegido otras formas muy distintas de ingreso económico y de apego al trabajo agrícola que pone en cuestión la sociedad rural e indígena. ${ }^{3}$

Las movilidades geográficas tienen diferentes efectos comunitarios, familiares e individuales dependiendo de su carácter local, regional, nacional e internacional, influyendo así en sus ingresos económicos, consumo, inversión en vivienda o tierras, expectativas y cambios socioculturales. En su ir y venir, conforman establecimiento y movilidad constante, circuitos migratorios complejos transnacionales por donde circulan dinero, personas, objetos, expectivas y equipajes socioemocionales. Las causales se vinculan con la búsqueda de un trabajo, de un ingreso, de mayor salario y, en general, con la mejora de los aspectos económicos, lo que determina de alguna manera los tiempos de su ausencia, la duración y alcance de sus proyectos migratorios.

Las percepciones sobre los beneficios que la migración trae consigo son diversas. Su complejidad es reflejo de procesos de realidad de reciente aparición. Hay quienes consideran que las remesas económicas permiten la adquisición de parcelas, solares y la modificación de la vivienda, es decir, que ayudan a elevar los niveles de vida de la familia. Pero por otro lado, hay otros que creen que no ha transformado en nada las condiciones económicas de los coyutecos, pues la gente sigue migrando, o están aquellos que valoran los aspectos más visibles como los culturales - que los jóvenes se niegan a trabajar la tierra, que se fomenta el desarraigo y los migrantes de retorno traen nuevas prácticas en relación al tiempo libre y el divertimento, así como la modificación de sus cuerpos o el consumo de sustancias o alcohol—.

${ }^{3}$ Como ha sido documentado ampliamente para los casos de Chiapas (Aquino, 2012), Oaxaca (Velasco, 2002), el Estado de México (Nicolás, 2019) y Guerrero (Boruchoff, 1999).

EntreDiversidades. Revista de Ciencias Sociales y Humanidades, Vol. 9, Núm. 1 (18), enero-junio 2022. Páginas: 176-199 ISSN-e: 2007-7610. https://doi.org/10.31644/ED.V9.N1.2022.A07 
Por tanto, el fenómeno migratorio internacional genera contextos complejos diversos y acelera procesos de cambio en los roles de las mujeres y las cargas de trabajo privado y público, en las percepciones sociales respecto a las movilidades, el dinero y el trabajo, y en las formas de socializar a nivel local de los familiares de migrantes y entre los que se encuentran allende la frontera.

\section{Bibliografía citada}

Alanís Enciso, Fernando y Alarcón Acosta, Rafael (coords.) (2016). El ir y venir de los norteños. Historia de la migración mexicana a Estados Unidos (Siglos XIX-XXI). Ciudad de México, México: El Colegio de Michoacán, El Colegio de San Luis, El Colegio de la Frontera Norte.

Alarcón Acosta, Rafael (1988). "El proceso de norteñización: impacto de la migración internacional en Chavinda Michoacán”, en Calvo, Thomas y López, Gustavo (eds.). Movimientos de población en el occidente de México. México, D.F., México: Centro de Estudios Mexicanos y Centroamericanos, El Colegio de Michoacán, pp. 337-357.

Aquino Moreschi, Alejandra (2012). De las luchas indias alsueño americano. Experiencias migratorias de jóvenes zapotecos y tojolabales en Estado Unidos. México, D.F., México: Publicaciones de la Casa Chata, Centro de Investigaciones y Estudios Superiores en Antropología Social, Universidad Autónoma Metropolitana Unidad Xochimilco.

Arizpe S., Lourdes (1985). Campesinado y migración. México, D.F., México: Secretaría de Educación Pública.

Bauman, Zygmunt (2008). Archipiélago de excepciones. Madrid, España: Editorial Katz.

Besserer Alatorre, Federico (2013). "Regímenes de sentimientos y la subversión del orden sentimental. Hacia una economía política de los afectos". Nueva Antropología. Revista de Ciencias Sociales, 27 (81), julio-diciembre, pp. 55-76. También disponible en: http://www.scielo.org.mx/pdf/na/v27n81/v27n81a4.pdf

Boruchoff, Judith (1999). "Equipaje cultural: objetos, identidad y transnacionalismo en Guerrero y Chicago”, en Mummert, Gail (ed.). Fronteras fragmentadas. México, D.F., México: El Colegio de Michoacán, Centro de Investigación y Desarrollo del estado de Michoacán, pp. 499-517.

Bourdieu, Pierre y Sayad, Abelmalek (2017). El desarraigo. La violencia del capitalismo en una sociedad rural. Argentina: Siglo XXI Editores.

Chenaut, Victoria (2010). "Los totonacas de Veracruz. Población, cultura y sociedad", en Córdova Plaza, Rosío (coord.). Atlas del patrimonio cultural de Veracruz. Tomo II. México, D.F., México: Gobierno del Estado de Veracruz, Comisión del Estado de Veracruz para la Conmemoración de la Independencia Nacional y la Revolución Mexicana, Universidad Veracruzana, pp. 45-66. Disponible en: https://www.sev.gob.mx/servicios/publicaciones/ colec veracruzsigloXXI/AtlasPatrimonioCultural/02TOTONACAS.pdf (Consultado el 6 de marzo de 2017).

EntreDiversidades. Revista de Ciencias Sociales y Humanidades, Vol. 9, Núm. 1 (18), enero-junio 2022. Páginas: 176-199 ISSN-e: 2007-7610. https://doi.org/10.31644/ED.V9.N1.2022.A07 
Chenaut, Victoria (2014). Género y procesos interlegales. México, D.F., México: El Colegio de Michoacán, Centro de Investigaciones y Estudios Superiores en Antropología Social.

Cruz de Echeverría Loebell, Stephanie (2014). El norte en la mira. Imaginarios y cultura de migración en Jalpan de Serra, Querétaro. Tesis para obtener el grado de Maestría en Estudios Culturales. El Colegio de la Frontera Norte. Disponible en: https://colef. repositorioinstitucional.mx/jspui/bitstream/1014/124/1/TESIS\%20-\%20Cruz\%20 de\%20Echeverria\%20Loebell\%20Stephanie.pdf (Consultado el 5 de junio de 2017).

De Leone, Lucía (2016). "Imaginaciones rurales argentinas: el campo como zona de cruce en expresiones artísticas contemporáneas". Cuadernos de Literatura [en línea], 20 (40), pp. 181-203. doi: https://doi.org/10.11144/Javeriana.cl20-40.irac (Consultado el 19 de noviembre de 2018).

García Martínez, Ariel (2014). Cultura e identidad indígena en Veracruz: juventudes en el Totonacapan en el siglo XXI. Xalapa, Veracruz, México: Consejo Nacional para la Cultura y las Artes, Instituto Veracruzano de la Cultura.

Gatti, Luis María y Chenaut, Victoria (1987). La costa totonaca: cuestiones regionales II. Cuadernos de la Casa Chata Volumen 158. México, D.F., México: Centro de Investigaciones y Estudios Superiores en Antropología Social, Secretaría de Educación Pública.

Gil Méndez, J. Jesús (2012). La costumbre de cultivar y moverse al norte. Circuito migratorio migro agricola en el valle de Ixtlán, Michoacán. Zamora/Sahuayo, México: El Colegio de Michoacán, Universidad de La Ciénaga del Estado de Michoacán de Ocampo.

Gobierno del Estado de Veracruz (GEV) y Secretaría de Finanzas y Planeación del Estado de Veracruz (SEFIPLAN) (2016). Sistema de información municipal. Cuadernilllos municipales. Coyutla [en línea]. Disponible en: http://ceieg.veracruz.gob.mx/wp-content/ uploads/sites/21/2016/05/Coyutla.pdf (Consultado del 25 de abril de 2021).

Griego, Daniela, et al. (2003). Memoria de encuentros indígenas en Veracruz. 1995-2001. Xalapa, Veracruz, México: Movimiento Agrario Indígena Zapatista-Asesoría y Servicios Rurales (MAIZ.ASER), Consejo Nacional para la Cultura y las Artes, Instituto Veracruzano de la Cultura.

Hirai, Shinji (2014). "La nostalgia. Emociones y significados en la migración transnacional". Nueva Antropología. Revista de Ciencias Sociales [en línea], 27 (81), pp. 77-94. Disponible en: https://revistas-colaboracion.juridicas.unam.mx/index.php/nuevaantropologia/article/view/16051/14372 (Consultado el 23 de marzo de 2015).

Instituto Nacional de Estadística y Geografía (INEGI) (2021). Migración [en línea]. Disponible en: http://www.cuentame.inegi.org.mx/poblacion/migracion.aspx?tema=P (Consultado el 8 de mayo de 2021).

Levitt, Peggy (s/f). Cultura y migración. Más allá de la cultura como producto. Harvard University. Mimeografiado.

Levitt, Peggy (2001). The transnational villagers. Berkeley, California, United States of America: University of California Press. 
Levitt, Peggy y Glick-Schiller, Nina (2004). "Perspectivas internacionales sobre migración: conceptualizar la simultaneidad”. Migración y desarrollo [en línea], 2 (3), pp. 60-91. doi: https://doi.org/10.35533/myd.0203.pl.ngs (Consultado el 9 de septiembre de 2010).

Lomnitz, Larissa Adler de (1976). Cómo sobreviven los marginados. México, D.F., México: Siglo XXI.

Massey, Douglas, et al. (1987). Return to Aztlan. The Social Process of International Migration from Western Mexico. United States of America: University of Califonia Press.

Mendoza Ramírez, Luisa Quiahuitl Xochitl (2014). "El auge, consolidación y decadencia de la industria petrolera en Poza Rica, Veracruz. Transformaciones poblacionales y migración laboral", en La construcción del futuro: los retos de las Ciencias Sociales en México. Memorias de 4 Congreso Nacional de Ciencias Sociales. V. Procesos sociodemográficos y estudios de migración [en línea]. San Cristóbal de Las Casas, Chiapas, México: Centro de Estudios Superiores de México y Centroamérica, Universidad de Ciencias y Artes de Chiapas, pp. 568-578. Disponibleen: https://repositorio.cesmeca.mx/handle/11595/857? show=full (Consultado el 18 de octubre de 2016).

Mino García, Fernando (2011). La nostalgia de lo inexistente. El cine rural de Roberto Gavaldón. México, D.F., México: Consejo Nacional para la Cultura y las Artes.

Moctezuma, Sergio (2008). Ambiente, cafeticultura y migración: los indígenas totonacos de Naranjales, Mecatlán, Veracruz. Tesis para obtener el grado de Maestría en Antropología Social, Universidad Iberoamericana. Disponible en: https://www.aacademica.org/sergio. moctezuma/13.pdf (Consultado el 18 de septiembre de 2011).

Morin, Edgar (2004). Introducción al pensamiento complejo. México, D.F., México: Gedisa.

Muñoz González, María de los Ángeles (2004). Organización totonaca, cultura y derechos indigenas en procesos de desarrollo local. El caso de la Organización Tres Corazones. Tesis para obtener el grado de Maestría en Desarrollo Rural, Universidad Autónoma Metropolitana. Unidad Xochimilco. También disponible en: https://repositorio.xoc.uam.mx/jspui/ handle/123456789/1013

Muñoz González, María de los Ángeles y Casados González, Estela (2008). “Fue bien. Él sí regresó. Migración indígena en Veracruz. El caso de los totonacos del municipio de Coyutla”. Regiones y desarrollo sustentable, Año VI, Núm. 11, julio-diciembre, pp. 103-115. Nava Tablada, Martha Elena (2010). Migración y desarrollo rural en cuatro regiones campesinas de Veracruz. Xalapa, Veracruz, México: El Colegio de Veracruz.

Nicolás Flores, Patricia (2019). "Vicisitudes de la reinserción sociocultural. Migrantes retornados a la región mazahua del Estado de México", en Rivera Sánchez, Liliana (ed.). ¿Volver a casa? Migrantes de retorno en América Latina. Debates, tendencias y experiencias divergentes. Ciudad de México, México: El Colegio de México, pp. 313-350. También disponible en: https://cedua.colmex.mx/assets/docs cedua/original/137/h 2019 Masferrer Prieto CapituloCES.PDF?1593193746

Oehmichen, Cristina (2003). "Espacio urbano y segregación étnica en la Ciudad de México". Papeles de Población, 7 (28), abril-junio, pp. 181-197. 
Pérez Monterosas, Mario (2001). "El trabajo como vida y como idea: la migracion laboral internacional en una comunidad rural michoacana”, en Patińo, Elsa y Castillo, Jaime (comps.). Trabajo y migración. México: Red Nacional de Investigación Urbana, Benemérita Universidad Autónoma de Puebla, pp. 175-190.

Pérez Monterosas, Mario (2013). "Tejiendo redes para futuras movilidades: las interacciones y el capital social en la migración emergente de México a los Estados Unidos”. Sociológica México, Año 28, Núm. 78, enero-abril, pp. 139-170. También disponible en: http://www.sociologicamexico.azc.uam.mx/index.php/Sociologica/article/view/54/46

Pérez Monterosas, Mario (2016). "Migración internacional de retorno y repercusiones emocionales en Coyutla, Veracruz". Clivajes. Revista de Ciencias Sociales [en línea], Núm. 5, pp. 70-98. Disponible en: $\underline{\text { https://clivajes.uv.mx/index.php/Clivajes/article/ }}$ view/2001/3674 (Consultado el 13 de enero de 2017).

Pérez Monterosas, Mario (2018a). "Las migraciones en el norte de Veracruz, México. Redes, rutas y ruralidades". Si somos americanos. Revista de Estudios Transfronterizos [en línea], 18 (2), pp. 34-52. Disponible en: https://www.sisomosamericanos.cl/index.php/ sisomosamericanos/article/view/859 (Consultado el 15 de diciembre de 2018).

Pérez Monterosas, Mario (2018b). “Irse no es migrar, migrar es ir a trabajar': dinámicas migratorias complejas de los totonacas de Coyutla, Veracruz”, en Sánchez, Carolina, Carlos Zolla y Genoveva Roldán (coords.). Transferencias salariales y migración indígena. Ciudad de México, México: Programa Universitario de Estudios de la Diversidad Cultural y la Interculturalidad, Instituto de Investigaciones Económicas, Universidad Nacional Autónoma de México, pp. 193-209. También disponible en: https://www. nacionmulticultural.unam. $\mathrm{mx} /$ portal/pdf/publicaciones novedades editoriales/libro transferencias salariales migracion indigena.pdf

Ramírez Melgarejo, Ramón (1994). "La política nacional y la política de los totonacos". Anuario IX. Instituto de Investigaciones Histórico-Sociales. Universidad Veracruzana, pp. 237-258. También disponible en: https://cdigital.uv.mx/handle/123456789/8552

Ramírez Melgarejo, Ramón (2002). La politica del Estado mexicano en los procesos agrícolas $y$ agrarios de los totonacos. Veracruz, México: Instituto de Investigaciones Histórico-Sociales, Universidad Veracruzana. También disponible en: https://cdigital. uv.mx/handle/123456789/8874

Rivera Sánchez, Liliana (2004). “Transformaciones comunitarias y remesas socioculturales”. Migración y desarrollo [en línea], 2 (2), pp. 62-81. doi: https://doi.org/10.35533/ myd.0202.lrs (Consultado el 24 de marzo de 2006).

Rivera Sánchez, Liliana (2012). Vinculos y prácticas de interconexión en un circuito migratorio entre México y Nueva York [en línea]. Buenos Aires, Argentina: Consejo Latinoamericano de Ciencias Sociales. Colección becas de investigación. Disponible en: http://biblioteca. clacso.edu.ar/clacso/becas/20120507115705/RiveraSanchez.pdf (Consultado el 7 de junio de 2014). 
Rouse, Roger Christopher (1989). Mexican Migration to the United States: Family Relations in the Development of a Transnational Migrant Circuit. Tesis para obtener el grado de Doctorado en Filosofía, Stanford University.

Schutz, Alfred (2012a). "El forastero. Ensayo de psicología social”, en Sabido Ramos, Olga (ed.). El Extranjero. Sociología del extraño. Madrid, España: Sequitur, pp. 27-42.

Schutz, Alfred (2012b). "La vuelta al hogar", en Sabido Ramos, Olga (ed.). El Extranjero. Sociología del extraño. Madrid, España: Sequitur, pp: 43-56.

Sennet, Richard (2000). La corrosión del carácter. Las consecuencias personales del trabajo en el nuevo capitalismo. Barcelona, España: Anagrama.

Tarrius, Alain (2000). "Leer, describir, interpretar las circulaciones migratorias: conveniencia de la noción de 'territorio circulatorio'. Los nuevos hábitos de la identidad”. Relaciones. Estudios de Historia y Sociedad [en línea], 21 (83), pp. 37-66. Disponible en: https://www. redalyc.org/pdf/137/13708303.pdf (Consultado el 14 de marzo de 2017).

Velasco Ortiz, Laura (2002). El regreso de la comunidad: migración indígena y agentes étnicos. Los mixtecos en la frontera México-Estados Unidos. México, D.F., México: Colegio de México, Colegio de la Frontera Norte.

Velázquez Hernández, Emilia (1995). Cuando los arrieros perdieron sus caminos. La conformación regional del Totonacapan. México: El Colegio de Michoacán.

Vera Cortés, Gabriela (2014). Historia, cultura y desastres en el Totonacapan: construcción de la vulnerabilidad social. Xalapa, Veracruz, México: Consejo Nacional para la Cultura y las Artes, Instituto Veracruzano de la Cultura.

\section{Entrevistas etnográficas}

Pérez Monterosas, Mario (2012a). La experiencia con la migración. María. Entrevista Coyutla, Veracruz. [Comunicación personal]. 22 de noviembre de 2012.

Pérez Monterosas, Mario (2012b). La experiencia con la migración. Juan Martínez. Entrevista Coyutla, Veracruz [Comunicación personal]. 22 de noviembre de 2012.

Pérez Monterosas, Mario (2012c). La experiencia con la migración. Enrique López. Entrevista Coyutla, Veracruz [Comunicación personal]. 22 de noviembre de 2012.

Pérez Monterosas, Mario (2012d). La experiencia con la migración. Manuel. Entrevista Coyutla, Veracruz. [Comunicación personal]. 22 de noviembre de 2012.

Pérez Monterosas, Mario (2012e). La experiencia con la migración. Nemesio. Entrevista Coyutla, Veracruz [Comunicación personal]. 22 de noviembre de 2012. 